\title{
Innovations in anesthesia education: the development and implementation of a resident rotation for advanced airway management
}

\section{Nouveautés dans la formation en anesthésie: le développement et la mise en ouvre d'un système de stages de prise en charge avancée des voies aériennes pour résidents}

\author{
Edward Crosby, MD · Alan Lane, FCARCSI
}

Received: 6 July 2009/Accepted: 14 September 2009/Published online: 22 October 2009

(C) Canadian Anesthesiologists' Society 2009

\begin{abstract}
Purpose This article incorporates the following objectives: to review the current evidence regarding the occurrence and management of difficult airways, to outline the role for alternative technology in the management of the difficult airway, to provide a rationale for structured airway rotations in anesthesia residency training, to discuss the barriers to establishing the rotations, to outline issues that must be considered and resolved to enhance these rotations, and to share the experience we have gained over the last decade of offering an airway rotation in the Department of Anesthesiology at the University of Ottawa. Principal findings The incidence of difficult laryngoscopy and intubation has not changed in recent times. Persistent attempts at direct laryngoscopy are associated with low success rates and patient complications. The early use of alternative devices improves the likelihood of success in airway management and reduces the potential for patient injury. Alternative airway management devices are increasingly available to Canadian anesthesiologists, and there is an expectation that anesthesiologists will possess the necessary skills to safely manage the difficult airway with these alternative devices.

Conclusions Anesthesia training programs must provide residents with the skill sets necessary for safe independent practice in airway management. The changes in the scope and reality of residency training have exposed limitations
\end{abstract}

E. Crosby, MD $(\varangle) \cdot$ A. Lane, FCARCSI

Department of Anesthesiology, University of Ottawa,

The Ottawa Hospital - General Campus, Suite 1401,

501 Smyth Road, Ottawa, ON K1H 8L6, Canada

e-mail: ecrosby@sympatico.ca in the traditional mentoring model of residency training; consequently, many programs have responded by offering sub-specialty rotations. In particular, advanced airway management rotations are being offered increasingly to residents in the Canadian training programs. Considerations and strategies to develop and implement a structured airway management program during anesthesia residency are discussed.

\section{Résumé}

Objectif Cet article intègre les objectifs suivants : passer en revue les données probantes actuelles concernant l'incidence et la prise en charge des voies aériennes difficiles, résumer le rôle des technologies alternatives dans la prise en charge des voies aériennes difficiles, proposer une justification pour la mise en æuvre de stages structurés pour la prise en charge des voies aériennes durant la résidence en anesthésie, présenter les obstacles à la mise en place de stages, exposer les questions à prendre en compte et à régler pour améliorer les stages, et faire part de l'expérience que nous avons acquise au cours des dix dernières années dans le cadre d'un système de stages pour la prise en charge des voies aériennes au sein du département d'anesthésiologie de l'Université d'Ottawa.

Constatations principales L'incidence de cas de laryngoscopie et d'intubation difficiles n'a pas changé récemment. Des tentatives répétées de laryngoscopie directes sont associées à des taux faibles de réussite et à des complications pour les patients. L'utilisation précoce d'appareils alternatifs améliore la probabilité de réussite de la prise en charge des voies aériennes et réduit le potentiel de lésions chez le patient. Les anesthésiologistes canadiens ont de plus en plus accès à des dispositifs alternatifs de prise en charge des voies 
aériennes, et il est attendu que les anesthésiologistes auront les compétences nécessaires pour prendre en charge de façon sécuritaire les voies aériennes difficiles à l'aide de ces dispositifs alternatifs.

Conclusion Les programmes de formation en anesthésie doivent permettre aux résidents d'acquérir les ensembles de compétences nécessaires à prendre en charge de façon sécuritaire et indépendante les voies aériennes. Les modifications des objectifs et de la réalité de la résidence en anesthésie ont rendu manifestes les limites du modèle traditionnel de mentorat de la résidence; pour cette raison, nombre de programmes offrent désormais des stages dans les sous-spécialités. En particulier, des stages en prise en charge avancée des voies aériennes sont de plus en plus souvent offerts aux résidents dans les programmes de formation canadiens. Les considérations et stratégies nécessaires à développer et mettre en ouvre un programme structuré de prise en charge des voies aériennes pendant la résidence en anesthésie sont présentées.

\section{Introduction}

The method traditionally used to train anesthesia residents in Canada was based on the apprenticeship model. It evolved and was adapted from that model first proposed for the training of surgical residents by William Osler to the Board of Trustees of the Johns Hopkins Hospital which was then enthusiastically adopted and promoted by William Halsted. ${ }^{1,2}$ The traditional teaching method evolved from that proposed by Osler, Osler did not propose the adapted or evolved model. In the adapted apprenticeship model, the resident learned the principles and performance of anesthesia both in the operating room and in the clinical examination setting by observing and then imitating the actions of a skilled mentor. This process was supported to a varying degree by didactic lectures and independent reading. Though it has evolved over the intervening years, the apprenticeship model is still viewed by many as the current standard for both surgical and anesthesia training. University-directed residency programs afforded this model the structure, standardization, and stability it required to train current residents.

There have been recent changes in the scope and reality of Canadian residency training that have exposed the limitations in the apprenticeship model. First, resident duty hour reductions were imposed resulting in fewer working and on-call hours in both the hospital and the operating room. It is possible that pressure will be exerted on training programs in the near future to further limit duty hours. In the United States, the Institute of Medicine has recently proposed further reductions to the resident duty hour limits than those previously imposed in 2003 by the Accreditation Council for Graduate Medical Education. ${ }^{3}$ Even though some have argued that the benefit to training and safety has been unconfirmed with the reductions imposed to date and the merit of further reductions is open to question, nevertheless, it is possible that reductions will be imposed in some jurisdictions. ${ }^{4}$ To address current shortages of physician manpower, training programs in many Canadian centres have also increased significantly in size. In all likelihood, the larger number of residents in the programs coupled with the reduced number of training hours has reduced their exposure to clinical experiences, sub-specialist mentors, and training opportunities.

To coincide with the reduction in the number of training hours, there has been an enormous increase in training expectations. Residents are not only expected to learn a multitude of new technologies (ultrasound for central lines, advanced airway management, regional anesthesia), but now they are also expected to fulfill an increased number of roles on completion of training (the CanMEDS roles). Further, efficiency initiatives in the operating room have put considerable pressure on hospitals to maximize operating room throughput at the least cost, and this impacts on technical skills training for residents. The operating room is now a less tolerant and less supportive training environment. Finally, patient safety initiatives and public expectations have advanced the notion that patient injury should not result as residents acquire and practice skills on real patients. The public expectation is that outcomes will be uniformly good, and there is little tolerance for novice errors.

Issues related to the teaching of residents by the mentoring staff also impact the quality of training. Innovations are slowly integrated into practice, and their implementation varies both over time and in different centres. ${ }^{5}$ Residents may be exposed to the newest technologies and practices in one centre and completely miss similar opportunities in another. Clinical teaching has been described as variable, unpredictable, immediate, and lacking in continuity. ${ }^{6}$ What is learned one day is not necessarily supported or reinforced the next. The perception of their mentoring role is inconsistent amongst different staff; some staff may have less interest in resident training than others. Finally, formal faculty development initiatives are relatively new in many programs and nonexistent in others; as a result, staff mentors who wish to enhance their own technical or teaching skills may face significant barriers.

In response to the issues outlined above, the structure inherent in many Canadian anesthesia training programs has been increased. Sub-specialty rotations have been instituted for many domains to ensure the residents are at least exposed to the patients, techniques, and sub- 
specialists practicing in those domains. In this way, there is increased expectation that the residents will make contact with the sub-specialist mentors who possess the new knowledge and innovative skills of these domains. These days, advanced airway management rotations are being offered progressively more to residents in the Canadian training programs. The Department of Anesthesiology of the University of Ottawa has offered a rotation in airway management to its residents since 1998. Despite the duration of its offering, the rotation continues to evolve and very much remains a work in progress. In the following article, we include a review of the current evidence regarding the occurrence and management of difficult airways, an outline of the role for newer technology in the management of the difficult airway, a rationale for resident airway rotations, a discussion regarding the barriers to establishing airway rotations, an outline of some of the issues to consider and resolve to enhance the efficacy of these rotations, and an account of some observations we made and experience we gained throughout the last decade.

\section{Residency training and the difficult airway: the environmental scan}

Does the difficult airway persist as a problem in clinical anesthesia practice?

In all probability, there has been little change in the recent past in the incidence of difficult laryngoscopy and intubation when using a direct laryngoscope. More than a decade ago, Rose and Cohen reviewed the experience of 18,205 patients undergoing general anesthesia with endotracheal intubation and reported that difficult laryngoscopy (defined as tracheal intubation requiring $>2$ attempts at direct laryngoscopy) occurred in $1.8 \%$ of patients and intubation failed in $0.3 \% .^{7}$ More recently, a number of authors have reported that the occurrence of failed intubations was from 0.26 to $0.9 \%$ of all anesthetics when direct laryngoscopy was the primary technology employed to facilitate intubation. $^{8-10}$ If direct laryngoscopy fails at the outset, often persistent further attempts are also unsuccessful. A decade apart, Rose and Mort reported that persistent attempts at direct laryngoscopy to secure tracheal intubation were associated with incrementally lower rates of success, higher rates of patient morbidity, and a significant increase in the complications when more than two attempts were made. ${ }^{7,11}$ In similar eras, Hung and Connelly respectively reported that early use of alternative devices improved the success of airway interventions and reduced the likelihood of patient injury compared with persistent efforts with the direct laryngoscope. ${ }^{8,12}$
Our ability to predict difficult intubation using bedside screening is poor. ${ }^{13}$ Unanticipated difficult and failed intubation will occur with the direct laryngoscope, and the evidence suggests that it is best managed by alternative strategies in order to enhance the likelihood of success and reduce patient injury. Persistent efforts with the direct laryngoscope in the setting of failed direct laryngoscopy are consistently associated with both a low expectation of success and increased patient injury. When unanticipated difficulties do occur, anesthesiologists must be prepared to intervene with practiced alternatives to the direct laryngoscope.

Salvage of the difficult airway: what is the role for alternative technologies?

Hung et al. reported on the salvage effectiveness of the Trachlight $^{\mathrm{TM}}$ (Laerdal Medical, Toronto, Canada) in 206 patients with a documented history of difficult intubation or anticipated difficult airways (Group 1) and in 59 anesthetized patients with an unanticipated failed laryngoscopic intubation (Group 2). ${ }^{12}$ Tracheal intubation was successful in all but two of the Group 1 patients and in all of the Group 2 patients; the tracheas of the two Group 1 Trachlight $^{\mathrm{TM}}$ failures were intubated successfully using a fibreoptic bronchoscope. Connelly et al. retrospectively reviewed the experience of managing unanticipated difficult airways in 447 patients. $^{8}$ Four airway management techniques were utilized by care-providers to manage the airway: persistence with direct laryngoscopy; a laryngeal mask airway (LMA); Bullard $^{\mathrm{TM}}$ (Olympus Canada Inc, Markham, Canada) laryngoscopy; or fibreoptic bronchoscopy (FOB). The success rates were: repeat direct laryngoscopy, 22\%; LMA, 87\%; Bullard $^{\mathrm{TM}} 84 \%$; and FOB, $90 \%$.

Heidegger et al. reported an assessment of a simple algorithm for response to unanticipated difficulties in 13,248 patients undergoing tracheal intubation at an acute care hospital. ${ }^{14}$ If intubation was planned with direct laryngoscopy, a maximum of two attempts at intubation were permitted; if these attempts were unsuccessful, oral fibreoptic intubation was then attempted. Intubation failed with both direct and fibreoptic laryngoscopy in only six patients (0.045\%; 95\% confidence interval 0.02-0.11\%). Burkle et al. retrospectively reviewed the experience of 37,482 patients who underwent general anesthesia with attempted direct laryngoscopy. ${ }^{9}$ The tracheas of 161 patients $(0.43 \%)$ could not be intubated by direct laryngoscopy alone. The most commonly used alternative airway device, the fibreoptic bronchoscope, was successful in 92 of the $99(92.9 \%)$ patients in whom it was attempted. In one institution, Combes et al. undertook a prospective evaluation of a predefined algorithm for unanticipated difficult airway management. $^{10}$ Difficult or impossible ventilation was 
managed with the intubating laryngeal mask airway (ILMA). In the event of difficult intubation, the Eschmann ${ }^{\circledR}$ Tracheal Tube Introducer (Smiths Medical Int Ltd, Kent, UK) (gum elastic bougie) was used. Six difficultventilation patients required the ILMA before completion of the first intubation step. One hundred cases of unexpected difficult airway were recorded $(0.9 \%)$ among 11,257 intubations. The tracheas of 80 patients were intubated using the gum elastic bougie, and the tracheas of 13 patients underwent a blind intubation through the ILMA.

Existing and emerging data suggest that using alternatives to the direct laryngoscope may be more effective and safer than persistent efforts with the direct laryngoscope when an unanticipated difficult airway is experienced. The evidence also would support the conclusion that similar good outcomes may be achieved with different alternative technology. In most instances, experience with the alternative technique is likely of greater importance than the actual technique chosen.

Evaluation of new and alternative technologies for difficult airway management

The technique employed by most anesthesiologists to facilitate routine tracheal intubation involves the use of the direct laryngoscope. It is effective even in many difficult intubation scenarios. It is also the standard against which both existing and new alternative devices should be measured. If we are to propose that the application of a new alternative airway technology should be encouraged in clinical practice, we should be able to demonstrate an advantage of that technology over the direct laryngoscope to justify both the cost of acquisition and the requirement to learn new techniques. Although the accumulating experience with alternative devices for the salvage of difficult airway continues to be very encouraging, further study is required both to confirm the utility of these devices for this purpose and to support strong recommendations that they be employed in preference to the direct laryngoscope. Further studies large enough to yield meaningful data are required to compare the outcomes of the various innovative technologies with both the direct laryngoscope and with other forms of innovative technology. To encourage adoption of these new technologies, the results of these studies should demonstrate an advantage or benefit either to the patient or to the system, particularly in higher-risk populations.

Mihai et al. performed a quantitative review to assess the outcomes of studies evaluating rigid fibreoptic laryngoscopy systems. ${ }^{15}$ Only the Bonfils ${ }^{\mathrm{TM}}$ (Karl Storz Co, Tuttlingen, Germany) and CTrach ${ }^{\mathrm{TM}}$ (The Laryngeal Mask Company Ltd, Jersey, Channel Islands) had homogenous data and first-time intubation success rates above $90 \%$ in normal patients. The Bonfils ${ }^{\mathrm{TM}}, \mathrm{CTrach}^{\mathrm{TM}}$ and Glide$\operatorname{scope}^{\mathrm{TM}}$ (Verathon Medical ULC, Burnaby, Canada) had first-time success rates above $90 \%$ in patients predicted or known to be difficult to intubate. Mihai et al. concluded that the currently available data did not provide strong evidence that these devices should supersede standard direct laryngoscopy for routine or difficult intubation and further high-quality research studying relevant patients needed to be done to create such evidence. Actually, some of the required evidence is now becoming available and continues to be both encouraging and increasingly convincing.

Sun et al. randomized 200 patients to tracheal intubation by either direct laryngoscopy or the Glidescope ${ }^{\mathrm{TM}}$ after the best glottic view (Cormack and Lehane) was obtained for all patients by a different anesthetist using a direct laryngoscope. ${ }^{16}$ In the Glidescope ${ }^{\mathrm{TM}}$ group (GS), the assessed laryngoscopy grade was improved in the majority of patients with an initial grade $>1$ and in all but one of the patients who were grade 3 . The mean time to intubate was $30 \mathrm{sec}$ in the direct laryngoscopy (DL) group and $46 \mathrm{sec}$ in the GS group, but the mean time to intubate in grade 3 patients was $47 \mathrm{sec}$ for the DL group and $50 \mathrm{sec}$ for the GS group. In most patients, the GS provided a glottis view equal to or better than that of direct laryngoscopy, but tracheal intubation took somewhat longer $(16 \mathrm{sec})$. In patients with difficult laryngoscopy, tracheal intubation time was the same.

In a randomized controlled clinical trial, Maharaj et al. compared the ease of intubation using the Airtraq ${ }^{\mathrm{TM}}$ (AT) (King Systems Corp, Noblesville, USA) with the Macintosh laryngoscope (DL) in patients at increased risk for difficult tracheal intubation. ${ }^{17}$ Forty patients who possessed $\geq 3$ characteristics indicating an increased risk for difficult intubation were randomly assigned to undergo intubation using a DL $(n=20)$ or AT $(n=20)$ laryngoscope. Intubation was performed by anesthetists experienced in the use of both laryngoscopes. The tracheas of all patients in the AT group were successfully intubated; however, tracheal intubation with the direct laryngoscope was unsuccessful in four patients in the DL group, but successful with the AT. Compared with the DL, the AT reduced the duration of intubation attempts, the need for additional maneuvres, the intubation difficulty score, the degree of hemodynamic stimulation, and the occurrence of minor trauma.

Jungbauer $e t$ al. prospectively compared the outcome of tracheal intubation in 200 patients with a Mallampati score of III or IV using either a Berci-Kaplan ${ }^{\text {TM }}$ (Karl Storz) video laryngoscope (VL) or a DL. ${ }^{18}$ The VL provided a better view of the cords, a higher success rate, faster intubations, and less need for optimizing maneuvres. Also, Marrel et al. evaluated the role of a VL and that of direct laryngoscopy in 80 morbidly obese patients by comparing 
the view at laryngoscopy, the duration of intubation, the number of attempts needed, and the minimal oxygen saturation reached during the intubation process. ${ }^{19}$ The view achieved with the VL was significantly better in 28 patients and the duration of intubation was shorter.

High-quality studies are emerging that support and encourage the routine use of alternatives to the direct laryngoscope in the setting of anticipated difficult intubation. If failure rates are considered, the odds ratio for failure with the direct laryngoscope in the setting of difficult intubation is significantly higher than that experienced with the alternatives. As well and as noted, published data supports the conclusion that salvage interventions in the setting of an unanticipated difficult intubation with a practiced alternative are likely to be associated with better outcomes than those achieved with persistent use of a direct laryngoscope. In both anticipated and unanticipated difficult intubation, residents entering practice should be trained and equipped with the skills necessary to intervene with alternatives to the direct laryngoscope.

What is the current status of alternate airway technology use in Canada?

There are no current data regarding the availability of alternate airway technology, but Canadian anesthesiologists have been surveyed regarding this issue on two occasions in the last decade. In 2000, Jenkins et al. surveyed active members of the Canadian Anesthesiologists' Society, and the survey results indicated that a wide range of alternate devices were available to anesthesiologists in the centres where they practiced. ${ }^{20}$ Wong surveyed the same group in 2003 and received a similar pattern of responses. ${ }^{21}$ On this latter survey, the respondents were also asked to indicate their comfort level with the alternate airway devices available to them. With the exception of the Bullard $^{\mathrm{TM}}$ laryngoscope and retrograde techniques, selfreported comfort levels ranged from 72 to $93.5 \%$. Of particular interest was the finding that resident physicians often reported being as comfortable as staff physicians with many devices, and they reported being more comfortable than staff physicians with the lighted stylet. Although we do not have data on technology released to the market subsequent to these surveys, it is likely that these are also increasingly widely distributed and available.

Alternative devices are commonly if not yet uniformly available to anesthesiologists in Canada, and many practitioners who have access to the devices indicate they are comfortable using them. Whether they are as competent as they are comfortable with the devices has not been determined in any objective fashion. Sparse as it is, the preponderance of evidence suggests that clinicians have limited ability to accurately self-assess their own performance. This inability to accurately self-assess is prevalent and occurs at all points in the performance spectrum. ${ }^{22}$ Although most clinicians are inclined to hold an overly favourable view of their own ability, in fact it is reported that estimates of skill levels may be inversely related to performance actually measured by objective testing. ${ }^{23}$ Also, when allowed to compare their own performance with more expert practitioners, more skilled performers tend to assess their skill deficiencies more capably than less skilled performers. ${ }^{24}$ Attempts to evaluate performance or competence based on responses to a survey may be of limited value, as it is likely that accuracy in such assessments will be provided only with objective assessments.

Residents in Canadian training programs will be exposed to a variable range of new airway technology, and the training elements will vary from program to program. As well, the staff skill sets are likely to be non-homogenous, with some staff being considerably skilled with alternative technologies and others being less accomplished. It is unreasonable to expect the residents to achieve competency in the entire range of airway technology available to them; therefore, some consideration should be given to establishing a minimal competency kit during training. The competency kit could be consistent for all residents rotating through the airway rotation or consideration could be given for flexibility in the curriculum to allow for individualizing the skills kit.

\section{The minimal competency kit during training}

Physicians providing airway care to patients should be familiar with and practiced in alternative techniques to face mask and bag for ventilating the lungs and direct laryngoscopy for intubating the trachea. It cannot reasonably be expected that residents will receive instruction in the full extent of alternative technology available for airway management. However, they should receive instruction across a range of technology. It is our view that a minimal skills set during training should include instruction with the following devices: direct laryngoscope and adjuncts to the direct laryngoscope (stylets, introducers, and bougies), an extraglottic device (including supraglottic devices, such as the laryngeal mask airways and retroglottic devices, such as laryngeal tubes), a rigid fibreoptic or video laryngoscope, and a flexible fibreoptic or video intubating system. As well, it is our opinion that a lighted stylet provides value in many difficult airway scenarios and may be arguably included in the minimal skills set. Training in the performance of invasive airway maneuvres must be provided during anesthesia residency, and it is our view that this may be reasonably provided in a laboratory, workshop, or simulator setting. 


\section{Background considerations for a structured rotation in airway management}

What are the expectations regarding training and care in airway management?

None of the following organizations delineates specific objectives or expectations regarding airway training during education and training in anesthesiology: Anesthesiology Education Committee of the Royal College of Physicians and Surgeons of Canada; the American Board of Anesthesiology; or the European Board of Anaesthesiology, Reanimation and Intensive Care., ${ }^{1,2,25}$ Outlined as a specific objective under the CanMeds "Medical Expert Role" by the Royal College Committee is the expectation that the resident will demonstrate competence in all technical procedures, including airway management, by the completion of training; no more explicit guidance is offered. Although the European Board suggests minimum target numbers for a number of technical procedures, such as spinal anesthesia, epidural anesthesia, arterial catheterization, and central venous catheterization, no mention is made of either basic or advanced airway techniques. ${ }^{25}$

Despite the fact that the authorities responsible for governing and assessing training of anesthesia providers have yet to explicitly provide direct recommendations regarding instruction in airway management during training, a number of national societies or consensus groups have advocated for such a role by the anesthesia training programs. ${ }^{26-29}$ Other societies or consensus groups, while not advocating for the training role, clearly expect that practitioners will possess the necessary skills to safely manage the difficult airway. ${ }^{30,31}$ As well, experts reviewing both open and closed claims expect practitioners to have the necessary skills to manage the difficult airway and are critical if they do not. In the most recent evaluation of closed airway claims in the American Society of Anesthesiologists Closed Claims database, care was judged to be less than appropriate in nearly half of the difficult airway claims. ${ }^{32}$ Failure to intervene effectively and in a timely fashion in both anticipated and unanticipated difficult airways resulted in a significant proportion of the successful claims registered.

To meet the expectations of practice, instruction in advanced airway management should be offered during anesthesia training, with residents being assigned to dedicated airway rotations. ${ }^{33,34}$ Hung and Kim surveyed Canadian anesthesia program directors and reported that

\footnotetext{
${ }^{1}$ Objectives of Training and Specialty Training in Anesthesiology. Anesthesiology Education Committee, Royal College of Physicians and Surgeons of Canada, Ottawa, Ontario, 2000.

2 Booklet of Information. Certification, Subspecialty Certification, Recertification, Maintenance of Certification. American Board of Anesthesiology, Raleigh, North Carolina, March 2008.
}

four of 15 programs had a mandatory airway rotation in 1996. A follow-up survey in 2002 determined again that four of 14 responding programs offered an airway rotation. ${ }^{35}$ An e-mail survey of program directors was carried out in the winter of 2008-2009 by the one of the authors (ETC) to ascertain the current status of advanced airway training in the Canadian programs. Nine of the 17 anesthesia training programs in Canada offered a rotation in advanced airway training (residents from the Northern Ontario medical school are assigned to the rotation in Ottawa); one of the remaining eight anticipated commencing a program in the 2009-2010 academic cycle. It is encouraging that more programs are providing residents the opportunity to participate in structured airway rotations. Unfortunately, since there is no curriculum guidance, each program must resolve to establish its own course outline and training strategies.

The rationale for an airway rotation during anesthesia training

In all likelihood, the incidence of the difficult airway will continue to be a relatively infrequent event in the experience of most anesthesia providers. In order to prevent or limit harm to the patients involved, responding to such an occurrence requires a response that is appropriate and timely and delivered with technical facility. Residents entering practice will be expected to emerge from training with the knowledge and skill set to manage both the anticipated and the unanticipated difficult airway with integrated response schema. In the past, it was assumed that airway management skills and knowledge would be largely acquired on the job whenever a training opportunity arose. It was expected that most trainees would be guided by mentors over the course of a residency as they were exposed to a sufficient number of cases that would afford them the opportunity to learn and practice advanced airway techniques and achieve competency in the management of the difficult airway. As has been discussed, perhaps this assumption was never true, and now it is certainly viewed more pessimistically. ${ }^{36}$

Learning new techniques is a daunting task for all, and residents are no exception; to try new things is to risk failure and failure is ego deflating. ${ }^{37}$ The operating room is also a challenging learning environment, and through necessity there are countless distractions for the residents. Some residents may find the operating room to be an uncomfortable, stressful, or even hostile educational environment. There has been considerable work studying the effects of stress on learning potential, and it appears that an environment that is moderately stressful supports the greatest potential for learning and performance. However, in situations requiring fine motor control and complex 
cognition, even lower stress levels may be necessary to support training and teaching. A number of factors contribute to a high level of stress in the operating room and these may impact negatively on learning. Another issue for trainees is the need to satisfy the idiosyncratic demands of multiple consultants, which makes it difficult to establish a consistent approach to a technical task. Finally, it must be acknowledged that the operating room is a very expensive classroom. The cost of teaching complex tasks to anesthesia residents in the operating room is significant, and there may be considerable cost savings with the use of skills labs, workshops, and simulators to teach both basic and advanced skills. ${ }^{38}$

If we accept that there is an imperative to ensure that residents are provided with at least basic skills in advanced airway management, and we are willing to acknowledge the significant barriers that they face in achieving this goal, then an approach must be found to foster the development of these skills while limiting the impact of the barriers on the resident. Assigning the residents to a rotation in airway management under the guidance of interested and skilled mentors ensures that they will have an opportunity to learn and practice advanced airway skills in an environment which is supportive of that activity.

\section{The University of Ottawa airway rotation}

In 1998, to comply with the recommendations of a national consensus group and at the insistence of the residents, the Department of Anesthesiology of the University of Ottawa first began offering an airway rotation to residents in its training program. Residents in their second to fourth year of training are assigned to a one-month rotation. There are two co-directors, and the clinical instructors who volunteer to participate are asked to indicate the airway techniques they would be comfortable teaching the residents. Both residents and instructors are given a compact disc that includes an extensive library of published materials that present the scientific foundations for airway management. The curriculum is flexible and the residents are encouraged to self-direct the rotation so as to receive skills training in an assortment of technologies available to them. The residents are not expected to become expert in the range of technologies during their one-month rotation; rather, they will be provided with useful guidance on the use of the technologies by clinical instructors who are interested and experienced in their use. Over the course of their training, the residents will be afforded opportunities to continue to develop their skill sets. The level of instruction will vary depending on the experience of the resident. More advanced residents are expected to function at a higher skills level, and the rotation will be more likely to provide them with skill enhancement rather than acquisition. Lists are assigned to maximize the opportunities for applying the alternate technologies, and an attempt is made to limit the complexity of the cases to help the resident concentrate on the airway skills. If patients with anticipated difficult airways are recognized on the operating room list, the airway resident is more apt to be assigned to that list. The residents are assessed on a daily basis by the supervising staff, and their performance appraisal during the rotation is compiled from these evaluations by the resident site director. The residents are asked to evaluate the rotation, and these evaluations are returned to the program director. A composite summary of these evaluations is shared with the codirectors of the rotation annually.

The rotation has evolved during its offering and is still a work in progress as there are a number of deficiencies and limitations. Although the involved staff are volunteers and believed to be interested and competent in the use of the technologies, the mentors' skills are not objectively assessed. The residents may receive conflicting advice on the use of some of the technologies by different mentors, and while that divergence of opinion may occasionally be valuable, it may also prove to be confusing to a novice learning a new technique. No attempts are made to log the number or range of interventions made by the residents, and there is no objective pre- and post-rotation skills evaluation. Finally, although there is an assortment of mannequins available to the residents for skills training during the rotation and they are encouraged to practice with them, there is no organized skills lab conducted during the rotation.

\section{The acquisition, development, and assessment of technical skills}

Achieving competence in anesthesiology entails developing a combination of knowledge, technical skills, decision making, communication skills, and leadership skills. Acquisition and refinement of basic and advanced technical skills by the resident are central to the process of training as an anesthesiologist. Although much of what is required to become a competent anesthesiologist must be learned inside the operating room, some basic technical skills may be taught, practised, and even evaluated outside the operating room. Basic training in skills labs allows for more rapid development of skill sets and permits focus on higher-level training in the operating room. Also, a less stressful environment that is more conducive to learning will make it easier for the novice to acquire the necessary skills. Although staff teachers should likely play a role in the initial instruction in a basic skills lab, afterwards, much of the practice may occur without staff present. ${ }^{39}$ Staff guidance is likely most useful when the basic skills are transferred to the clinical environment and incorporated 
into more complex tasks in the operating room. Direct staff mentoring is also of considerable value when the skills and techniques move beyond the basic to the advanced. At this point, the quality of the staff skills influences the development of the trainee's skills. ${ }^{40}$

Technical skills are learned in three phases: cognitive, integrative, and automatic. ${ }^{41}$ The first phase, the cognitive phase, consists of watching and then making initial attempts to duplicate what was observed. At this stage, performance tends to be erratic and procedures are carried out in distinct steps. Individuals who are given a clear description and demonstration of the task may be more likely to master the new skill with fewer repetitions; multimedia presentations may assist in this regard. ${ }^{42}$ Innovations in teaching, such at the use of video-enabled technology may also provide additional benefit during the early phases of skills acquisition. With practice and feedback, the learner can integrate knowledge of the task into the appropriate motor behaviours, and the resulting performance becomes more fluid with fewer interruptions (integrative phase). In the final automatic stage, repetitive practice results in a smooth and autonomous performance of the procedure without the need for continuous cognitive input. It is now possible to focus on other aspects of the intervention with less distraction from the demands of the technical task.

The role of video-enabled technology in airway technical skills training

Video-enabled airway technology includes both the integration of existing intubation equipment (typically viewed through an eyepiece) with video systems allowing the image to be viewed on a monitor as well as the more recently developed video and optical intubation tools. This technology has provided us with enormous advantages while teaching and training residents in the airway rotation, and it has enhanced the ability of staff to assist trainees while they clinically manage difficult airway situations. By coupling Olympus ${ }^{\mathrm{TM}}$ (Olympus) flexible fibreoptic bronchoscopes and the Bullard ${ }^{\mathrm{TM}}$ rigid laryngoscope with standard surgical cameras and video monitors, we achieved video-endoscopy capability before integrated video systems were available (Fig. 1a, b) The resulting systems, although effective, were more cumbersome and demanding in terms of setup and application than the newer integrated systems. However, it is our view that the limitations of the systems themselves were more than offset by the advantages that they conferred on both teaching and clinical management.

A welcome innovation over the last several years has been the development of both rigid and flexible airway management systems with integrated video capabilities; narrative reviews of such systems have now been published. $^{43,44}$ A defining characteristic of the videolaryngoscopic techniques is the indirect view of the glottic opening rather than the direct line-of-sight from the eye to the target using direct laryngoscopy. Some of the videolaryngoscopic techniques require an unobstructed line-ofsight from the tip of the device to the target for optimal function, whereas others can bypass obstructions in the airway lumen. An adequate glottic view is generally easily obtained by these systems, and it is frequently superior to
Fig. 1 a An Olympus ${ }^{\mathrm{TM}}$ fibreoptic bronchoscope is attached to a Storz surgical camera (Karl Storz) to create a video-enabled bronchoscope. b A Bullard ${ }^{\mathrm{TM}}$ laryngoscope is attached to a Storz surgical camera to create a videoenabled laryngoscope. In this instance, it was used to place a double-lumen tube in a patient with a difficult airway for the purpose of lung isolation
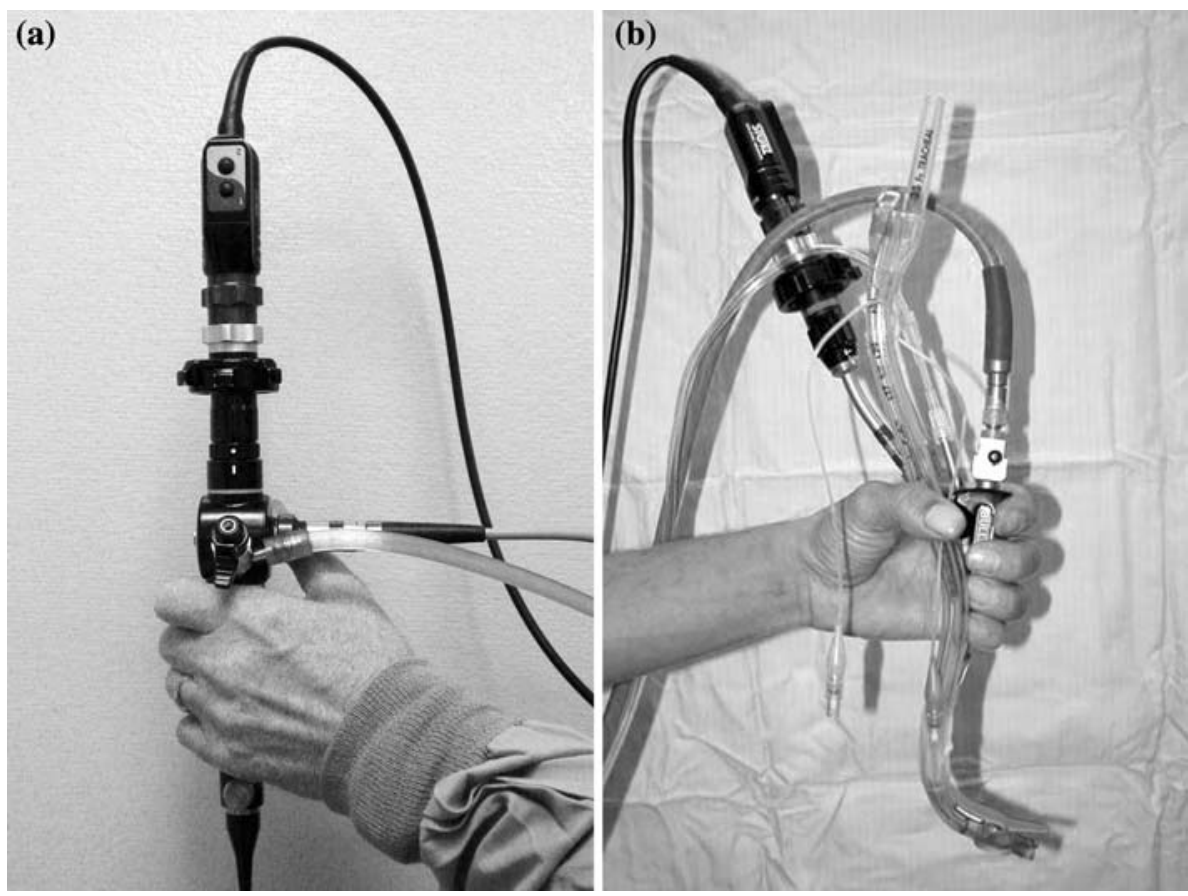
that obtained by direct laryngoscopy. However, endotracheal tube insertion is occasionally problematic and may occasionally represent a greater challenge than obtaining an adequate view. Both novice and experienced intubators seem to learn these systems easily, and a number of authors have reported rapid acquisition of skills among trainees. ${ }^{45,46}$

Howard-Quijano et al. compared the experiences of novices in a prospective randomized crossover study using a video laryngoscope or a direct laryngoscope. ${ }^{47}$ During video-assisted intubation, $69 \%$ of intubation attempts were successful compared with $55 \%$ of attempts with direct laryngoscopy. Esophageal intubations occurred in 3\% of video-assisted intubation attempts and in $17 \%$ of the intubation attempts using a direct laryngoscope. Similarly, in a simulated difficult airway, Low et al. reported that novice intubators demonstrated a reduction in intubation attempts, number of required repositioning maneuvres, and dental trauma when they were taught to use a video laryngoscope compared with being taught to use a direct laryngoscope. ${ }^{48}$

Shulman et al. assessed the role of a video system on the process of learning the use of the Bullard ${ }^{\mathrm{TM}}$ laryngoscope in experienced anesthesia providers who had no previous experience with the Bullard ${ }^{\mathrm{TM}} .49$ The providers were divided into two groups; subjects in the first group performed 15 intubations while looking directly through the eyepiece, while those in the second group used a camera to display the view on a video monitor. Both groups then performed a further 15 intubations looking directly through the eyepiece. When the first 15 intubations were considered, the laryngoscopy time was shorter in the video group; there were more successful first attempts at intubation, and there were fewer failed intubations than in the non-video group. There were no differences between the groups during the second 15 intubations. The authors concluded that the use of a video camera improved performance when the Bullard ${ }^{\mathrm{TM}}$ laryngoscope is first being taught; however, once basic facility with the instrument was achieved, the video camera seemed to provide less benefit.

Smith et al. compared the rate of progress of experienced anesthesia providers (trainees and consultants) who were taught flexible fibreoptic nasotracheal intubation with the aid of either a video-enabled system or a view-throughthe-eyepiece bronchoscope. ${ }^{50}$ Although all trainees eventually achieved similar rates of success, those using videoenabled systems did so after half the number of training exercises and intubation attempts; they took one-third the amount of time overall and experienced a quarter of the number of failures. The authors concluded that the use of video doubled the rate of skills acquisition by allowing more effective feedback from the mentor and more rapid development of effective movement patterns. Similarly, Wheeler et al. compared the impact of a video-assisted technique with traditional eyepiece fibreoptic intubation on the performance of second year residents learning fibreoptic intubation in pediatric patients. ${ }^{51}$ Compared with the residents in the traditional group, the residents in the video group achieved intubation more quickly; they were three times more likely to successfully intubate the trachea at any given time during an attempt, and they required fewer attempts per patient.

Video-enabled airway systems support the teaching of advanced airway management by permitting both mentor and trainee to share the same view of anatomy and to follow the progress of the airway intervention. As they are afforded this view, the mentor is able to provide explicit guidance relevant to the technique. Anatomic perspectives may be achieved with some of these technologies that would not be obtained with the direct laryngoscope, and the mentor is able to provide orientation and guidance to the trainee. We consider the use of video-enabled systems as being integral to any success we achieved during airway rotations with the systems compatible with video technology. We advocate their use.

The role of simulators in airway management training

There are a number of advantages to using models and simulators to teach airway management (Table 1). The value of simulator skills training relates to the notion of isoperformance. This notion implies that trainees may replace some training time performing the actual task in patients by spending time training on a model or a simulator. The total training time is similar, but a proportion of the time may be spent away from the clinical environment. This allows for skills training outside of the operating room. As well, it limits contact with patients at a time when the novice has only rudimentary skills, and it may also reduce the potential for patient injury. Naik et al. have

Table 1 Advantages of simulators in airway management training

No risk of patient exposure to injury

Interventions may be repeated often and in quick succession

Practice can be scheduled to suit timetables of mentors and students

Errors may be permitted without risk to patients

Technical tasks may be broken into elements without concerns about elapsing time

Interventions may be stopped to allow for feedback

Interventions may be repeated immediately after feedback to reinforce teaching

Uncommon scenarios may be modelled

Alternative devices and strategies may be compared for similar scenarios

Tasks of incremental difficulty may be constructed

Training exercises may be constructed to limit cognitive loading and distractions. 
reported that skills acquired from a simple training model are transferable to the clinical environment. ${ }^{52} \mathrm{~A}$ simple "choose the hole model" was used to teach residents fibreoptic bronchoscope manipulation skills. When subsequently assessed with anesthetized patients, modeltrained residents demonstrated a faster time to intubation, improved intubation success rate, and better technique compared with those who received only didactic training.

A range of models and simulators exist which may be used for airway management training. They differ in terms of both construct and fidelity. Many mannequins are designed for resuscitation training rather than airway management training, and the anatomical airway construct may be somewhat deficient. Rosenthal assessed small desktop mannequins used for teaching basic airway management and found the main limitations concerned the artificial look and feel of the mannequins as well as the failure to simulate an obstructed airway that responds appropriately to basic airway maneuvres. ${ }^{53}$ Some models may be designed specifically for certain aspects of airway training (flexible fibreoptic intubation, surgical airways) and may be less useful for other technical training roles.

Fidelity refers to the degree to which a model approximates reality; it is not always necessary to employ a high fidelity model. Friedmann et al. reported that residents acquiring cricothyrotomy skills may be trained to a similar degree with either a low fidelity (corrugated tubing) or high fidelity simulator (full scale simulator with anatomically correct larynx). ${ }^{54}$ They suggested that novices may benefit from a simple model as it allows them to better focus on the basic steps in the process. Studies among trainee surgeons acquiring both endo-urological and microsurgical skills have also shown that low fidelity and high fidelity models confer the same degree of benefit to basic skills training, and both are significantly superior to didactic sessions. ${ }^{55,56}$ As long as the key constructs of the task are faithful to reality, the model should offer potential for practice and training of the most relevant aspects of the skill.

Model training may be useful for tasks which are likely to be required relatively infrequently and for which there may not be frequent opportunities for training on patients. Kory et al. compared the basic airway management skills of a group of senior medical residents trained during their first year using scenario-based training with a computerized patient simulator with a group trained conventionally (experience accumulated as clinical opportunities arose) ${ }^{57}$ The groups were tested during their PGY3 year with a standardized respiratory arrest scenario. The group trained in the simulator performed significantly better. The authors concluded that 2 years of traditional training was not sufficient to achieve the same proficiency in basic airway skills as could be achieved with simulator training. This may have been due to the relatively low frequency of the event and the resulting limited opportunities to practice the techniques.

Although simulators may be less useful if trainees are going to be performing multiple interventions in a relatively short period, they may be useful for initial training in advanced and complex skills or if the procedure is particularly high risk or consumes rare or valuable resources. Seymour et al. randomized surgical residents to virtual reality (VR) laparoscopic training or to control, non-VR training until they had achieved expert criterion levels. ${ }^{58}$ All subjects then performed laparoscopic cholecystectomy supervised by a staff surgeon who was blinded to training status. VR-trained residents performed the test maneuvres faster and more effectively, and they were less likely to require guidance to make progress. Similar studies have demonstrated the benefit of training with VR airway simulators for novice fibreoptic intubators. Residents who receive training on a VR airway simulator acquire skills more rapidly and perform at a higher level compared with those who receive didactic training alone. ${ }^{59-61}$

In order to support airway skills development, anesthesia trainees should have access to mannequins that are suitable for training. During initial skills acquisition, basic models and trainers are likely to be sufficient; however, as goals and objectives become more detailed and advanced, the use of higher fidelity models and simulators may be useful. The significant differences between available trainers may have an impact on the effectiveness of training. Some training exercises with special requirements call for task-specific models and they are optimal for some training purposes. ${ }^{52}$ Model fidelity is of less importance for devices where the focus of the "training" is on the acquisition of skills related to the device itself (bronchoscope) than it is for those where a more lifelike mannequin is important to the technique (laryngeal mask airways). Departments considering the purchase of mannequins and simulators should conduct a training needs analysis. It is likely that at least two models will be necessary to teach a range of alternate strategies for airway management.

Impact of the student on the manner, rate, and level of skills acquisition

There are a number of publications that address the process of learning a new skill, the impact the process has on the type of trainee (novice resident learning basic skills $v s$ more experienced resident learning advanced skills), and the struggle some trainees experience when acquiring new technical skills. Plummer and Owen observed that novice subjects undergoing endotracheal intubation training generally demonstrated rapid early learning, but the rate of learning then reached a plateau. They speculated that specific educational interventions at that point may more 
effectively restore the rate of skill acquisition than simply having the trainee repeat attempts. ${ }^{62}$ Additionally, when the trainees shifted their efforts from one airway trainer to another, the odds of success were significantly reduced in the initial attempts on the new trainer. The authors hypothesized that rudimentary skills developed by a novice on a trainer may be trainer-specific; in effect the novice trainee becomes adept at intubating the model rather than adept at the skill of intubation. These trainer-specific skills may not translate readily to other environments, including clinical scenarios. In the formative phase of new skill development, there may be value in working with a number of models.

Residents appear to acquire airway skills at different rates even when placed in similar circumstances. De Oliviera Filho analyzed the outcomes of 895 endotracheal intubations performed by seven novice anesthesia residents to determine the number of interventions necessary to be performed before attaining an acceptable $(20 \%)$ failure rate. ${ }^{63}$ Four of the seven residents reached the acceptable failure rate after an average of $43 \pm 33.49$ attempts; the other three did not achieve the acceptable failure rate even after $>100$ attempts. Some novices will struggle considerably with the challenges of endoscopy despite amassing considerable experience. Grantcharov and Funch-Jensen assessed the learning curve patterns in novice surgical residents with limited laparoscopic experience as they performed multiple task repetitions of basic laparoscopic skills on a virtual reality trainer. ${ }^{64}$ A small number $(5.4 \%)$ demonstrated proficiency from the beginning; the majority $(70.3 \%)$ achieved predefined expert criteria after two to nine task repetitions; some (16.2\%) demonstrated improvement in performance but were unable to achieve proficiency even after ten repetitions. The last group (8.1\%) consistently underperformed and showed no tendency for skills improvement.

Although most trainees achieve success in the development of their technical skills, a small group will struggle to reach proficiency with both basic and advanced skills within the experience frame required by their peers. Some will continue to experience difficulty long after their peers have successfully met the challenge of the new techniques. If such a struggle were apparent to the mentors during assignment to an airway rotation, possibly these trainees could benefit from more intensive mentoring and further practice. It is also possible that the objectives of the rotation could be revised in this instance to focus on the development of a more limited skill set. Kenton advanced the notion of a "struggling" algorithm, suggesting that there may be value in explicitly and repetitively reminding trainees of the need to re-evaluate their performance when they are experiencing difficulty with technical interventions. ${ }^{65}$ Specific suggestions from the observing mentor may prove exceptionally valuable to the struggling trainee who possesses the insight to listen.

Estimating the requisite number of airway interventions to achieve competence

Wang et al. evaluated the effects of endotracheal intubation experience on paramedic student proficiency using longitudinal, multi-centre data. ${ }^{66}$ Although the majority of the students actually performed fewer than ten intubations each, the authors estimated that proficiency should be obtained after about 30 interventions. This estimate was outside of the range of the data collected and did not account for the plateau which typically emerges after rapid early improvements in skills. Tatiyanupunwong determined the minimum number of cases of endotracheal intubations that medical students must perform in order to achieve an acceptable level of competence. ${ }^{67}$ A $90 \%$ probability of successful intubation required at least 16 attempts, with an upper estimate of 33 attempts. A 95\% probability required at least 22 attempts at intubation with an upper estimate of 49. Mulcaster et al. also determined the number of tracheal intubations that novices were required to perform before achieving acceptable levels of competence. ${ }^{68}$ Statistical modelling indicated that a $90 \%$ probability of success required $47 \pm 11.2$ attempts. Once again, this estimate was outside of the range of data collected, and the model assumed that the same learning process continued from trials 35-50.

Konrad constructed a group learning curve to describe the performance of first-year anesthesia residents during their initial attempts at intubation. ${ }^{69}$ Although there was a marked improvement in skill and outcomes after 20 attempts, the group reached the $90 \%$ success rate only after a mean of 57 attempts; even after 80 attempts, $18 \%$ of the residents required assistance with subsequent attempts. This is consistent with the report of De Oliviera Filho who determined the number of intubation events that novice anesthesia residents needed to perform before attaining an acceptable (20\%) failure rate. ${ }^{63}$ Half of the residents achieved the acceptable failure rate after an average of $43 \pm 33.49$ procedures; the rest failed to do so even after $>100$ attempts. Smith et al. assessed the skills acquisition of 12 anesthetic trainees as they performed 20 nasotracheal intubations on anesthetized patients. ${ }^{70}$ The half-life of the curve for the trainees was nine endoscopic intubations. The model inferred that the trainees would achieve successful intubations within the estimated expert time after five halflives (45 repetitions).

There is variation in the reports that provide estimates of the accumulated experience required by novice learners to achieve proficiency with intubation by direct laryngoscopy. In general, the reports from modelling exercises using the 
data from a limited number of novice intubations calculate smaller experiences than those reports collecting data from a larger number of novice intubations. It may be that the smaller evaluation series are biased by the rapid early skills acquisition phase and de-emphasize the fact that the rate of skills acquisition slows as experience accumulates. The larger evaluation series may more accurately represent the actual learning curves. It is likely that about 50 event repetitions are necessary before competence with tracheal intubation using a direct laryngoscope is achieved, and it is probable that a similar level of experience is necessary to attain competence with alternative devices.

Developing a statistical approach for measuring the competence of anesthesia trainees at airway procedures

We currently use the same assessment mechanism for residents in the airway rotation as that used for residents in other rotations in our training program. The supervising staff member completes a daily evaluation which is returned to the program site director's office for compilation into an aggregated assessment that is both qualitative and subjective. As airway rotations mature, ideally assessments will move to a more objective competencybased standard. It is preferable that the resident's performance evaluation during the rotation be structured to allow for educational interventions to address skills deficits identified in the process. Similarly, the final evaluation for the rotation should optimally measure the resident's skill set against a competency standard. We believe that the current daily evaluations allow for some measure of educational intervention during the rotation to address perceived deficiencies; however, this opportunity is diminished by the reality that the resident is assigned to multiple mentors. To allow for correction of skills deficits, the resident must receive timely feedback as to the nature of the deficit and carry that assessment forward to the next mentor and practice opportunity. The goal of a competency-based final assessment is difficult since no such standard has been described for Canadian training programs. Also, residents of highly variable experience currently are assigned to the rotation, and it is unreasonable to assume that a second-year resident will achieve skills and competence comparable to a fourth-year resident by rotation end.

A number of different strategies may be used to track and measure the rate that trainees acquire new airway skills. Most of these strategies measure outcomes against the number of interventions performed and compare the result with a standard of competency or expertise to determine the experience required by the average novice. If assessment of the individual trainee is ongoing during the skills acquisition phase, these analyses may provide the following feedback: reassurance that the trainee is on-track and performing within the range expected; recognition that the trainee is exceeding expectations and may be offered more challenging cases; or forewarning that remedial instruction may be warranted.

The number of technical interventions and their outcomes (success or failure) may be recorded in simple log books kept during the rotation. They provide residents with an objective measure of their experience and may highlight issues and deficiencies that may be addressed through subsequent training. The value of the log books beyond these strategic training imperatives is uncertain. A commonly reported analytic strategy for evaluating the acquisition of new skills is generating a learning curve. ${ }^{71,72}$ A learning curve has four phases. The starting coordinate represents commencement of training and defines where the performance of an individual practitioner begins. The curve then ascends and the gradient of this ascent (slope of the line) indicates how quickly the individual's performance improves. A steep learning curve implies a rapid uptake of the skill. Increments in performance improvement typically tend to be largest early in the experience and then become smaller as the degree of improvement with each event repetition is reduced and as the technique is refined. Assuming adequate aptitude on the part of the novice, a point is reached when the procedure can be performed independently and competently, and the rate of rise of the learning curve is significantly diminished. From this point, additional experience typically improves performance by very small increments and a plateau, or asymptote, is reached. The asymptote indicates the level at which the practitioner's performance has stabilized, and this likely indicates the performance level achieved by most experienced practitioners. Individual learning curves may be constructed during training and compared with a peer group learning curve to determine how skills acquisition is progressing relative to the comparator group (Table 2 and Fig. 2).

Cumulative sum (cusum) analysis is another statistical technique that is useful for distinguishing deviations from an acceptable failure rate. ${ }^{73}$ The cusum starts at zero and positive or negative increments are added to a cumulative score with each successive failure or success at a procedure. The cusum increases with failure and decreases with success; thus, success is indicated by a declining trend of the cusum, and failure by an increasing trend of the cusum. Acceptable and unacceptable failure rates are determined, and two boundary limits to the cusum are calculated. When the cusum declines below the lower boundary limit, then the true failure rate is not statistically different from the acceptable rate; if the cusum ascends to exceed the upper boundary limit, then the true failure rate is statistically significantly higher than the acceptable rate. If the cusum 
Table 2 Record of successful fibreoptic intubation in $<60 \mathrm{sec}$ by novice learner

\begin{tabular}{|c|c|c|}
\hline Trial \# & Success $\mathrm{Y} / \mathrm{N}$ & Cumulative success rate \\
\hline 1 & $\mathrm{~N}$ & 0 \\
\hline 2 & $\mathrm{~N}$ & 0 \\
\hline 3 & $\mathrm{Y}$ & 33 \\
\hline 4 & $\mathrm{Y}$ & 50 \\
\hline 5 & $\mathrm{Y}$ & 66 \\
\hline 6 & $\mathrm{~N}$ & 50 \\
\hline 7 & $\mathrm{Y}$ & 57 \\
\hline 8 & $\mathrm{Y}$ & 63 \\
\hline 9 & $\mathrm{Y}$ & 66 \\
\hline 10 & $\mathrm{~N}$ & 60 \\
\hline 11 & $\mathrm{Y}$ & 64 \\
\hline 12 & $\mathrm{Y}$ & 66 \\
\hline 13 & $\mathrm{Y}$ & 69 \\
\hline 14 & $\mathrm{Y}$ & 71 \\
\hline 15 & $\mathrm{~N}$ & 66 \\
\hline 16 & $\mathrm{Y}$ & 69 \\
\hline 17 & $\mathrm{Y}$ & 71 \\
\hline 18 & $\mathrm{Y}$ & 72 \\
\hline 19 & $\mathrm{Y}$ & 74 \\
\hline 20 & $\mathrm{Y}$ & 75 \\
\hline 21 & $\mathrm{Y}$ & 76 \\
\hline 22 & $\mathrm{~N}$ & 73 \\
\hline 23 & $\mathrm{Y}$ & 74 \\
\hline 24 & $\mathrm{Y}$ & 75 \\
\hline 25 & $\mathrm{Y}$ & 76 \\
\hline 26 & $\mathrm{Y}$ & 77 \\
\hline 27 & $\mathrm{Y}$ & 78 \\
\hline 28 & $\mathrm{Y}$ & 79 \\
\hline 29 & $\mathrm{Y}$ & 80 \\
\hline 30 & Y & 80 \\
\hline
\end{tabular}

stays between the two boundaries, then observations must be continued before a conclusion regarding performance can be confidently made. The advantage of plotting the cusum is that periods of acceptable (declining cusum) and unacceptable (ascending cusum) performance and trends in the performance of the trainee are obvious to both the trainee and the trainer.

Learning curves and cusum analysis set a realistic target for the number of interventions that must be completed before competency can be achieved and assumed by the average novice. They also allow for the estimation of acceptable failure rates. The disadvantage of both is that relatively large numbers of observations are required for meaningful accuracy. In many training situations, there is a desire for some early indication that the trainee's progress in the process of skills acquisition is satisfactory. This can

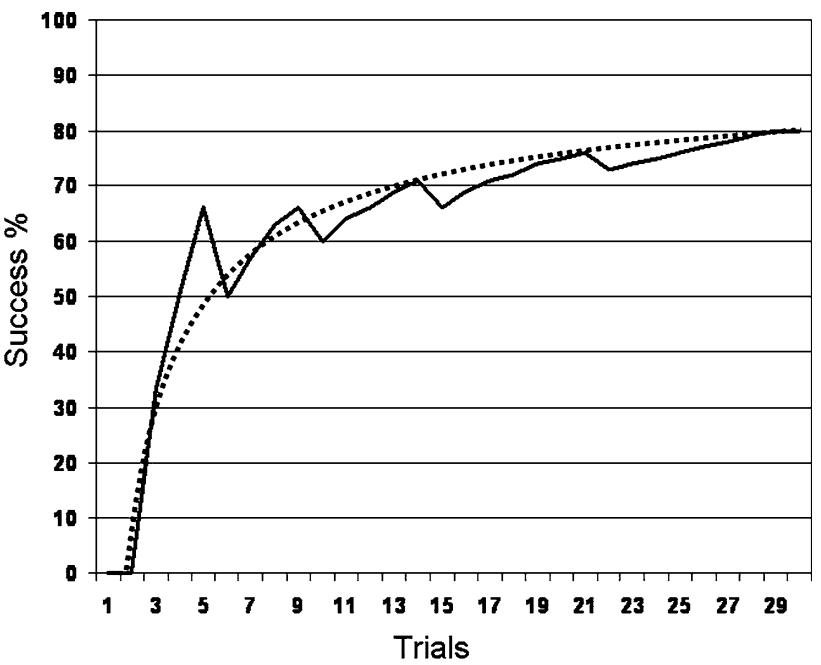

Fig. 2 An example of an individual learning curve (solid line) has been constructed for a hypothetical novice learner. The data in Table 2 are used to measure the cumulative success rate for fibreoptic intubation in $<60 \mathrm{sec}$ (competency grade) in the first 30 trials, and they are depicted against the group learning curve (dashed line) constructed from the experience of the peer group

allow for timely and remedial intervention and may result in improvement in skill acquisition. Harrison described grid analysis, i.e., a form of sequential analysis to track performance of tracheal intubation by novice intubators who individually performed relatively few interventions. ${ }^{74}$ Grid analysis allows for the assessment of an individual's progress during the process of skills acquisition and does so after a smaller number of events than required for either learning curves or cusum analysis. However, the literature on this form of analysis is very limited.

\section{Non-technical skills training in anesthesia and airway management}

Residency training places emphasis on the acquisition of the necessary knowledge and technical skills to ensure competent practice in anesthesia. However, satisfactory patient outcomes are more likely to occur if knowledge and technical skills are integrated into appropriately organized plans. Effective execution of these plans requires the development of a particular set of skills, including decision-making, communication, and team-work. These skills are sometimes described under the general heading as human factors, but they have also been described as nontechnical skills. ${ }^{75}$ It was once anticipated that these skills would develop somewhat spontaneously as residents progressed through training. However, it is now generally acknowledged that such is not the case, and training in this domain is as necessary and important as it is for technical skills training. 
Anesthesia has much in common with other risk-averse, high-reliability domains, such as aviation. Analyses of many aviation accidents revealed that unsafe flight conditions were frequently related to failures in pilots' nontechnical skills, rather than a lack of technical knowledge or flying ability. ${ }^{76}$ Specialist training programs labelled Crew Resource Management were designed to develop the use of non-technical skills to improve safety-critical behaviours on the flight deck. Concepts taught in Crew Resource Management include those relating to making inquiries, seeking relevant data, advocating actions, communicating proposed action plans, resolving conflicts, and decision-making. ${ }^{77}$ These concepts are especially relevant to training anesthesia residents and particularly useful in constructing approaches to managing the difficult airway.

Effective communication is integral to the successful resolution of both anticipated and unanticipated problems in anesthesia such as the difficult airway. Coordinating responses may be challenging in stressful environments and may break down when it is necessary to initiate unexpected non-routine procedures. Responses to critical situations may be more effectively delivered within the framework of a structured practised response ("salvage strategy"). Fletcher et al. have described an example of such a system that provides a structure for the discussion of potential airway scenarios during training and allows for either the development of personal response algorithms when difficult airways are encountered or, alternatively, the appropriate application of published difficult airway management plans. ${ }^{78}$

Our method of addressing the non-technical aspects of difficult airway management during the airway rotation has not been entirely adequate or satisfactory to date. Although we have generally made an effort to review difficult scenarios, potential responses, and the role of the alternative technologies with the residents during the airway rotation, we have yet to establish a core curriculum. Consequently, the teaching in this regard is fragmented and inconsistent from resident to resident.

\section{Considerations for the design and implementation of an airway rotation}

\section{Guidance and governance issues}

No Canadian national organization responsible either for training assessment or for setting standards in anesthesia practice is currently providing explicit guidance to direct the provision of airway management training during anesthesia residency. However, there is an expectation that anesthesia residents will emerge from training with competence in the domain of airway management and possess the knowledge, technical and non-technical skill sets to effectively and efficiently manage both the anticipated and unanticipated difficult airway. More than half of the Canadian training programs currently offer a mandatory airway rotation, typically during the PGY2-PGY4 years, and in the absence of a national curriculum, each program is responsible for generating its own course outlines.

Overcoming the barriers to establishing sub-specialty rotations

Despite the recent emphasis on the role of sub-specialty rotations to enhance anesthesia resident training, there has not been universal acceptance of the value of these rotations. Smith et al. reported on their efforts to design and implement a comprehensive learner-centred regional anesthesia curriculum at their institution. ${ }^{79}$ Implementation of the redesigned curriculum was initially met with barriers and logistical challenges, the most significant being overcoming the status quo, as faculty members were not consistently supportive of the initiative. A second challenge was convincing faculty to embrace newer styles of teaching, moving away from the traditional apprenticeship model toward learner-centred models of education. The provision of faculty development initiatives was a critical step to overcoming this obstacle. Our experience with respect to faculty perceptions was similar at the outset, but it is our impression that the concept of the airway rotation is now embraced by both the tutors involved and the department in general. Evaluations from the residents have consistently acknowledged their perception that there is solid support for the rotation from both anesthesia and surgical faculty. This support creates a positive learning environment in the operating room. Although there is an open offer of tutor support to all faculty members who wish to upgrade skills with any of the newer airway technology, we have not offered formal department-wide faculty development initiatives related to the airway rotation. This situation will change in 2009 as all faculty members will be offered formal in-training support at their request. There will also be department-wide updates beginning with a review of the content and set-up of all elements of our difficult airway carts.

The lack of availability of models and mannequins may provide an obstacle to skills training outside of the operating room. Internal funding and financial support from the Department of Anesthesiology at the University of Ottawa have assisted our airway rotation by funding the purchase of three task-specific mannequins, one each for general airway, fibreoptic bronchoscopy, and surgical airway (cricothyrotomy) training. Although the mannequins have provided opportunities for practice and skills development, they have been used to a variable degree by individual residents. They have afforded an opportunity for some residents to engage in 
remedial practice and have allowed for reinforcement training of some aspects of different skill sets.

An airway rotation needs a champion among the faculty, ideally a core group of champions. Depending on the environment, there may be inertia or even resistance to establishing the rotation that may not be short-lived. The department must be brought onside, as it will be very difficult for the rotation to succeed in the absence of such support. Departmental support will demonstrate to the other care-providers in the operating room that this is a fundamental aspect of anesthesia training and care. It is our perception that the majority of surgeons and nurses have come to accept that routine use of alternate airway technology is "just what we do". As well, some surgical groups, in particular the ear, nose, and throat (ENT) surgeons, have been very supportive of the concept of advanced skills training to the point of offering anesthesia residents the opportunity to attend their clinics for endoscopy training.

The rotation director must establish a basic rotation curriculum, set up infrastructure, secure training resources, enrol mentors, work to develop and preserve a supportive environment in the operating room, and respond to the evaluations of the residents. Providing the rotation director non-clinical time at the outset is an important resource imperative necessary to support the rotation and allow the fundamental requirements to be met.

Establishing the knowledge and technical objectives of the rotation curriculum

At the outset, consideration should be given to defining both the goals and objectives of the rotation and establishing a curriculum. Appendix 1 provides the general and specific objectives of the Ottawa rotation, which were formulated in a manner consistent with the CanMEDS roles (2007).

An extensive electronic library is provided to the residents (and mentors) at the beginning of the airway rotation, and the content is reviewed and updated about twice a year (Table 3). It is not intended that the articles be read in their entirety during the rotation, but it is expected that case and technique-directed reading will be done. As well, Benumof's Airway Management, 2nd edition, edited by Hagberg and Management of the Difficult and Failed Airway, edited by Hung and Murphy are available to the residents during the rotation.

Although there are general and specific technical objectives for the rotations, there can be some flexibility; for instance, in Ottawa the technical objectives for the rotation are resident-specific. A minimum skill set to be developed, enhanced, and assessed during the rotation typically would include instruction in the use of the laryngeal mask airways, adjuncts to the direct laryngoscope, a
Table 3 Content of electronic library (folders included)

Airway anatomy and physiology
Assessment
Best practices
Complications of airway management
Epiglottis
Gases, flows, and volumes
Guidelines for airway management
Obstructive sleep apnea and narcolepsy
Oxygen
Salvage of the difficult airway
Special populations
Surveys
Techniques

highly portable alternative (Trachlight ${ }^{\mathrm{TM}}$ ), and both rigid and flexible endoscopes. Table 4 lists the techniques and examples of the technologies that might be included in the minimal skills sets. There will obviously be a degree of program or institutional preference in the selection of the individual technologies. Video-enabled endoscopes are employed during the rotation. As well, a Berman-type intubating airway is typically used to facilitate the use of the flexible fibreoptic bronchoscopes, both in asleep and awake settings.

It is not expected that all of the residents will achieve the degree of competency to support independent use of all the

Table 4 Minimal skill set for resident airway rotation

Direct laryngoscopy and aids to intubation

Endotracheal tube introducers/bougies/stylets

Levering or flex tip laryngoscope blade

Extraglottic airways

Supraglottic airways, e.g., laryngeal mask airways

Retroglottic airways, e.g., laryngeal tube $\mathrm{TM}^{\mathrm{TM}}$

Rigid fibreoptic devices/video laryngoscopes/optical intubation devices

Airtraq $^{\mathrm{TM}}$

Bonfils ${ }^{\mathrm{TM}}$ retromolar fibrescope

Bullard $^{\mathrm{TM}}$ laryngoscope

Glidescope $^{\mathrm{TM}}$

McGrath $^{\text {TM }}$ (Aircraft Medical Ltd, Edinburgh, UK) laryngoscope

Pentax AWS ${ }^{\mathrm{TM}}$ (Pentax Medical Comp, Montvale, USA)

Optical stylet (Shikani ${ }^{\text {TM }}$ (Clarus Medical LLC, Minneapolis, USA) or Levitan $^{\mathrm{TM}}$ (Clarus))

Trachlight $^{\mathrm{TM}}$

Flexible fibreoptic or video intubating system (fibreoptic bronchoscope)

Infraglottic technique (laboratory, workshop, or simulator training)

Cricothyrotomy

Retrograde wire technique 
technologies that they are exposed to during the airway rotation. Studies assessing competencies with airway techniques suggest that at least 30 and often 50 or more repetitions are necessary to achieve greater than a $90 \%$ likelihood of success on subsequent repetitions. It is expected that the residents will receive the following: detailed instruction on the indications for use of the different technologies, including the proper setup and checkout of all the equipment used; instruction and supervision as to the use of the equipment; an opportunity to practise on models and use the equipment in clinical settings; feedback on their technical applications; and additional opportunities to employ the technology after feedback has been provided. The evaluations from the residents affirm that they have achieved most of these objectives in the majority of experiences and that they perceive themselves better able to set up and deploy the advanced airway technology after completion of the rotation. As noted, there is no objective evaluation of the skills developed by the residents during the rotation, and the subjective self-evaluations that we are relying on are prone to error.

What are the requirements for the mentors participating in the airway rotation?

The initial requirement for the mentors was, and remains, enthusiasm. At the outset, support for the rotation was not universal among the faculty, and the need to ensure a supportive learning environment for the residents was deemed absolute. Interested faculty members are asked to self-nominate and, although mentor skills are not assessed, they are asked to consider their own experience before identifying the techniques they feel comfortable teaching. Interested faculty are expected to have performed the airway technique at least 50 times, and they should be continuing to perform the technique on a regular basis. To develop and implement a technical skills training program effectively, it is our view that mentors must be able to identify the fundamental technical skills to be learned and must be able to teach and model perfect execution of the skills as well as create opportunities for supervised practice. To do this successfully, mentors must be competent with the technology and use it on a regular basis. Residents are provided with the list of mentors and mentor-approved techniques; accordingly, when they are assigned to a list with a staff supervisor, they are able to select from a number of appropriate techniques and prepare in advance.

At what stage in training should the residents be assigned to the airway rotation?

The majority of Canadian programs offering an airway rotation assign residents to the program when they are in their PGY2-PGY4 clinical years; this has been our practice as well. There are advantages and disadvantages of both the early and late rotations. The early rotation may be daunting for some of the more junior residents (early PGY2) with limited airway management skill sets, although most have handled it extremely well. Since the alternative techniques are often sufficiently different in their elements and execution, the early start in their advanced airway training may provide them with abundant opportunities for practice in the years ahead. Occasionally, it may be necessary to revise expectations during the rotation and concentrate on a more limited range of technical skills, but that adjustment seems to have been more resident-dependent than related to the year of training. Deferring the rotation until later in training may allow for considerable fine-tuning of already established skill sets, but it may also defer the opportunity to develop certain skills until late in the residency.

It is our view that the rotation can be scheduled at any point in the PGY2-PGY4 years, but, in most instances, there is probably no particular advantage to deferring it until late in the training cycle. Ultimately, the timing may depend on the ability of the program director to schedule it among the resident's many other rotations and the similar needs of the other residents in the program. We have contemplated offering both an early and a late rotation, but we would have to significantly enhance the resources already deployed to the rotation to achieve this goal, and the scheduling of the two rotations would not be without its challenges for the program director.

\section{Should specific patient consent be obtained?}

If the airway technique is part of a physician's routine practice, it has been our pattern not to seek specific patient consent for an intervention when it is being taught to residents. For example, if the staff physician is routinely using a Glidescope ${ }^{\mathrm{TM}}$ or a Trachlight ${ }^{\mathrm{TM}}$ as part of his/her practice, then seeking specific consent for its use is no more required than it would be for direct laryngoscopy, assuming that was the planned procedure. However, if the intervention is indicated but outside the range of experience that patients normally encounter (e.g., awake intubation), specific consent is obtained for the intervention.

Lessons learned over the first decade of the airway rotation

There are barriers to changing the status quo. In our case, the status quo was the traditional mentoring model of airway management training for residents. There was a concern that teaching was opportunistic, variable, and inconsistent and that some residents might experience 
exceptional educational opportunities while others might have severely deficient experiences. The initial proposal for an airway rotation was not accepted at the program level, and it was the residents themselves and the chief resident, in particular, who took it upon himself to ensure that the proposal was accepted at the second presentation. The residents have been the strongest advocates for the rotation from the very beginning. The enthusiasm of the rotation director(s) and the individual mentors was, and still is, extremely important. Initially, the enthusiasm helped to ensure that the rotation implementation was successful, even if support was not consistent at all levels. The enthusiasm has continued to be important because learning new techniques is difficult and failure is common. There can be reluctance even to try new techniques and technologies because the ego can withstand only so much deflation on some days. We believe that an experienced and enthusiastic mentor increases the rate of skill acquisition and adds perspective to the failed attempts ("You're learning, you're going to occasionally struggle, it happens to everyone."). Although it might be argued that a uniform and consistent approach is most helpful, we have not limited the number of mentors because we have come to recognize that different techniques are acceptable, that flexibility is indispensable, and enthusiasm is paramount. It has also been our experience that everybody wins with the rotation. Without fail, the mentors involved have been of the opinion that their involvement in the rotation has forced an increased exposure to the alternative devices and enhanced their familiarity and skills sets beyond what they likely would be otherwise. Others have published similar sentiments in the literature.

We have been challenged both internally and externally to demonstrate that the rotation is worth both the effort and resource expenditure. It is abundantly clear that the integration of new technology and techniques into anesthesia practice has had the potential to reduce patient injury and increase safety. It is our view that the more structured the educational initiative, the more experience and education is achieved across the ranks of the residents; the more educated and experienced the residents become with the technology and techniques, the better they will deal with future events as independent practitioners. Feedback from the residents has been consistent and positive over the years, whether it has been in the form of rotation evaluations or in the form of an anecdote that was shared after participating in an event that was successfully resolved because of a lesson or technique learned during the rotation.

We acknowledge the difficulty in applying specific metrics to the actual benefit of the rotation to the residents overall and to the individual residents based on their participation. With respect to assessment, the rotation is part of a larger organism-the teaching program in the Department of Anesthesiology, and assessments are based on the program model, which we believe has considerable merit. However, innovation and evolution are inherent in what we do, whether it is the practice of patient care, the education and assessment of our junior colleagues, or the organization of feedback that is provided to them. We do expect that future assessment techniques in medicine in general and anesthesia in particular will be more competency-based and objective in structure than they are at present; however, we have progressed significantly towards that goal in the last decade.

The next steps in the evolution of the airway rotation

As we contemplate the future direction of the airway rotation, a number of issues arise. The first and most obvious is the absence of a national curriculum for advanced airway training for anesthesia residents. If we accept that such experience is a necessary component of anesthesia residency training, it would seem obvious and intuitive that guidance regarding the curriculum to consider should be provided to programs as rotations are established and operated. Consideration should be given to faculty development initiatives to support the rotations as well as to encourage a wider dissemination of advanced skill sets among faculty who did not have the opportunity to participate in airway rotations and who may be interested in further developing their own skill sets. The use of regular labs and workshops is encouraged to allow for optimal skills acquisition and development. The integration of low fidelity (partial task trainers) with full scale simulators would support the objectives of the airway rotation to a considerable degree. Small models can be used to teach basic and advanced technical skills, while full scale simulation will allow for integration and evaluation of cognitive, psychomotor, and non-technical skills. The use of simulators may also be useful to reinforce and assess skill retention for infrequently performed procedures like surgical airways. Although we offer such workshops as a regular feature of our Continuing Medical Education events, so far we have not included them in a similar fashion in the airway rotation. It also makes sense to move to competency-based assessments and better methods to evaluate post-rotation skills to ensure that the rotations are meeting their objectives. These assessments cannot be completed in isolation from those at the program level, and consideration of competency-based training assessments in anesthesia is encouraged.

The provision of fellowship training in airway management would be the logical extension of an airway rotation. The end-product of such a fellowship would presumably be individuals with the knowledge base and 
technical and non-technical skill sets that would allow them to: function as experts in the clinical management of patients with difficult airways; provide for the education of anesthesiologists in the assessment and management of difficult or failed airways; engage in the evaluation and use of alternatives to the direct laryngoscope; and serve as the resources for local and national initiatives in the domain of airway management. Three anesthesia training programs in Canada currently advertise such a fellowship; University of Ottawa, University of Toronto, and Dalhousie University.

\section{Summary}

Difficult airways, whether they are anticipated or unanticipated, continue to be a clinical fact of life for anesthesia providers, and the available evidence clearly supports a role for alternative devices in the management of these occurrences. Technological advances over the last decade, in particular, have provided anesthesiologists with an impressive array of devices that may be deployed in the care of patients with a difficult airway. Anesthesiologists must be provided with the skill sets to provide safe care to these patients using these technologies, and an opportunity to develop these skills sets needs to be offered during residency training in an organized and systematic way. We have provided the background considerations, rationale, and goals and objectives for establishing and operating an airway rotation. Based on our decade of experience offering an airway rotation at the University of Ottawa, we have also shared our understanding of the barriers likely to be encountered when initiating a rotation as well as the operational realities of managing the program. In our view, the increasing challenges to resident training imposed by work hour restrictions and the expanding expectations residents encounter when they enter practice support establishing sub-specialty rotations in the anesthesia training program. Residents are well-served by them.

Disclosure Funded by the Department of Anesthesiology of the University of Ottawa. No considerations were received from the manufacturers, distributors, or vendors of the technologies discussed in this paper.

Competing interests None declared.

\section{Appendix 1: goals and objectives of the advanced airway rotation}

The Advanced Airway Management rotation consists of one month of training in the sub-specialty area of advanced airway management.
General objective

To provide the resident the opportunity to acquire the technical and non-technical skills necessary to provide safe and effective independent care to patients with challenging airways.

\section{Methods of learning}

When they begin the airway rotation, all residents will receive a $C D$ that includes a number of folders with literature presenting the scientific basis for advance airway management.

Residents will gain clinical experience in the assessment and provision of care to patients under the supervision of consultant anesthesiologists.

Residents will be assigned lists under the supervision of consultant anesthesiologists who have volunteered to participate in the airway rotation. The volunteer consultants have specified the techniques and technologies that they will be comfortable teaching, and a spreadsheet with the particulars will be provided to the residents.

Residents will be encouraged to collaborate with consultants in ENT, thoracic surgery, general surgery, plastic surgery, and other such relevant disciplines to gain additional perspective on the management of high-risk patients.

Three mannequins are available in the departmental library for independent practice.

\section{Evaluation}

Using the daily evaluations generated by the supervising staff members, the site director will develop a compilation of the general and specific objectives achieved by the residents.

\section{Specific objectives}

The resident will be provided assistance and clinical experience in evaluating and managing patients with a difficult airway who are undergoing anesthesia and intensive care.

The resident will be provided technical training with the advanced technology utilized in managing patients with difficult airways, including

- flexible endoscopes and video-endoscopes;

- rigid video laryngoscopes including the Glidescope ${ }^{\mathrm{TM}}$;

- lighted stylets and optical intubating stylets;

- laryngeal masks;

- retrograde intubation techniques (optional mannequin training); 
- percutaneous surgical management of the airway (optional mannequin training).

\begin{tabular}{l} 
Role \\
\hline $\begin{array}{r}\text { Medical } \\
\text { expert }\end{array}$
\end{tabular}

Key competencies

expert

The resident will acquire knowledge of the following topics:

1) Identification of the patient at increased perioperative risk of morbidity and mortality by reason of airway management issues.

2) Predictive value of preoperative airway assessment.

3) Identification of the difficult airway.

4) Specific evaluation strategies useful in high-risk populations.

5) The role of diagnostic imaging to facilitate evaluation of the airway.

6) Laboratory techniques useful in the evaluation of airway compromise.

7) Generation of an appropriate management plan in complex patients so as to optimize care and minimize the potential for adverse outcomes.

Communicator 1) Establish a professional relationship with peers, nursing and paramedical personnel, and patients and their families:

a) Demonstrate appropriate consideration and compassion.

b) Provide accurate information appropriate to the situation.

c) Ensure informed consent when necessary.

2) Effectively communicate with all members of the Perioperative Medicine Team:

a) Use effective verbal communication skills to ensure clear direction to the operating room support staff as to specific needs for optimal patient management.

b) Use clear and concise written communication skills to document patient assessments, consultations, interventions, postoperative management strategies, and progress notes.

Collaborator 1) Function effectively as an integral member of the Operating Room Team.

2) Consult effectively as required for optimal preoperative patient evaluation, optimization, and postoperative care, especially as it relates to airway management.

3) Utilize the abilities of all team members, including the ability to resolve conflicts, provide feedback, and assume a leadership role where appropriate.

4) Provide support and assistance to other staff and trainees regarding the appropriate indications and use of advanced airway technology.

5) Assist in generating appropriate postoperative plans designed to encourage optimal care and outcomes, while limiting the potential for adverse airway outcomes.
Appendix continued

\begin{tabular}{ll}
\hline Role & Key competencies \\
\hline Manager & 1) Utilize resources effectively to ensure timely and \\
thorough patient preparation for surgery and \\
optimal assessment. \\
2) Practice according to national standards for \\
evaluation and care of patients. \\
3) Work to ensure the appropriate technical and \\
personnel support is provided for advanced airway \\
training and the necessary resources are available \\
to ensure optimal patient care. \\
Health & 1) Provide expertise and leadership in maintaining \\
advocate & and improving the standards of training and \\
provision of care in the domain of airway \\
management. \\
2) Act as an advocate for the provision of the \\
resources and support necessary to ensure optimal \\
patient airway care. \\
1) Demonstrate the ability to critically review the \\
literature to understand and evaluate new \\
information and research. \\
2) Contribute to the learning of others. \\
3) Contribute to new knowledge, when possible. \\
Professional \\
1) Deliver the highest quality care with integrity, \\
honesty, and compassion. \\
patients and team members in the provision of \\
care.
\end{tabular}

\section{References}

1. Franzese $C B$, Stringer SP. The evolution of surgical training: perspectives on educational models from the past to the future. Otolaryngol Clin North Am 2007; 40: 1227-35.

2. Halsted WS. The training of the surgeon. Bull Johns Hopkins Hosp 1904; 15: 267-75.

3. Ulmer C, Wolman DM, Johns MM. Resident Duty Hours: Enhancing Sleep, Supervision, and Safety. Washington, DC: National Academies Press; 2008.

4. Blanchard MS, Meltzer D, Polonsky KS. To nap or not to nap? Residents' work hours revisited. N Eng J Med 2009; 360: 2242-4.

5. Crosby E. Innovation in medical practice: from new idea to standard of care. Can J Anesth 2008; 55: 328-36.

6. Parsell G, Bligh J. Recent perspectives on clinical teaching. Med Educ 2001; 35: 409-14.

7. Rose DK, Cohen MM. The airway: problems and predictions in 18,500 patients. Can J Anaesth 1994; 41: 372-83.

8. Connelly NR, Ghandour K, Robbins L, Dunn S, Gibson C. Management of unexpected difficult airway at a teaching institution over a 7-year period. J Clin Anesth 2006; 18: 198-204.

9. Burkle CM, Walsh MT, Harrison BA, Curry TB, Rose SH. Airway management after failure to intubate by direct laryngoscopy: outcomes in a large teaching hospital. Can J Anesth 2005; 52: 634-40. 
10. Combes X, Le Roux B, Suen P, et al. Unanticipated difficult airway in anesthetized patients: prospective validation of a management algorithm. Anesthesiology 2004; 100: 1146-50.

11. Mort TC. Emergency tracheal intubation: complications associated with repeated laryngoscopic attempts. Anesth Analg 2004; 99: 607-13.

12. Hung OR, Pytka S, Morris I, Murphy M, Stewart RD. Lightwand intubation. II. Clinical trial of a new lightwand for tracheal intubation in patients with difficult airways. Can J Anaesth 1995; 42: 826-30.

13. Shiga $T$, Wajima $Z$, Inoue $T$, Sakamoto A. Predicting difficult intubation in apparently normal patients: a meta-analysis of bedside screening test performance. Anesthesiology 2005; 103: 429-37.

14. Heidegger T, Gerig HJ, Ulrich B, Kreienbuhl G. Validation of a simple algorithm for tracheal intubation: daily practice is the key to success in emergencies-an analysis of 13, 248 intubations. Anesth Analg 2001; 92: 517-22.

15. Mihai R, Blair E, Kay H, Cook TM. A quantitative review and meta-analysis of performance of non-standard laryngoscopes and rigid fibreoptic intubation aids. Anaesthesia 2008; 63: 745-60.

16. Sun DA, Warriner CB, Parsons DG, Klein R, Umedaly HS, Moult $M$. The GlideScope Video Laryngoscope: randomized clinical trial in 200 patients. Br J Anaesth 2005; 94: 381-4.

17. Maharaj CH, Costello JF, Harte BH, Laffey JG. Evaluation of the Airtraq and Macintosh laryngoscopes in patients at increased risk for difficult tracheal intubation. Anaesthesia 2008; 63: 182-8.

18. Jungbauer A, Schumann M, Brunkhorst V, Borgers A, Groeben $H$. Expected difficult tracheal intubation: a prospective comparison of direct laryngoscopy and video laryngoscopy in 200 patients. Br J Anaesth 2009; 102: 546-50.

19. Marrel J, Blanc C, Fracarolo P, Magnusson L. Videolarygoscopy improves intubation condition in morbidly obese patients. Eur J Anaesthesiol 2007; 24: 1045-9.

20. Jenkins K, Wong DT, Correa R. Management choices for the difficult airway by anesthesiologists in Canada. Can J Anesth 2002; 49: 850-6.

21. Wong DT, Lai K, Chung FF, Ho RY. Cannot intubate-cannot ventilate and difficult intubation strategies: results of a Canadian national survey. Anesth Analg 2005; 100: 1439-46.

22. Davis DA, Mazmanian PE, Fordis M, Van Harrison $R$, Thorpe $K E$, Perrier $L$. Accuracy of physician self-assessment compared with observed measures of competence: a systematic review. JAMA 2006; 296: 1094-102.

23. Kruger J, Dunning D. Unskilled and unaware of it: how difficulties in recognizing one's own incompetence lead to inflated self-assessments. J Pers Soc Psychol 1999; 77: 1121-34.

24. Hodges B, Regehr G, Martin D. Difficulties in recognizing one's own incompetence: novice physicians who are unskilled and unaware of it. Acad Med 2001; 76: S87-9.

25. Section and Board of Anaesthesiology, European Union of Medical Specialists; Carlsson C, Keld D, van Gessel E, Fee JP, van Aken H, Simpson P. Education and training in Anaesthesiarevised guidelines by the European Board of Anaesthesiology, Reanimation and Intensive Care. Eur J Anaesthesiol 2008; 25: 528-30.

26. Crosby ET, Cooper RM, Douglas MJ, et al. The unanticipated difficult airway with recommendations for management. Can $\mathbf{J}$ Anaesth 1998; 45: 757-76.

27. Petrini F, Accorsi A, Adrario E, et al. Recommendations for airway control and difficult airway management (Italian). Minerva Anestesiol 2005; 71: 617-57.

28. Braun U, Goldmann K, Hempel V, Krier C. Airway management. Guidelines of the German Society of Anesthesiology and Intensive Care (German). Anaesth Intensivmed 2004; 45: 302-6.
29. Fischler M, Bourgain JL, Castre J, Bally B, Ravussin P, Richard $M$. Difficult airway: teaching strategies and techniques: question 7. Société Française d'Anesthésie et de Réanimation (French). Ann Fr Anesth Reanim 2008; 27: 54-62.

30. American Society of Anetshesiologists Task Force on Management of the Difficult Airway. Practice guidelines for management of the difficult airway: an updated report by the American Society of Anesthesiologists Task Force on Management of the Difficult Airway. Anesthesiology 2003; 98: 1269-77.

31. Henderson JJ, Popat MT, Latto IP, Pearce AC. Difficult Airway Society. Difficult Airway Society guidelines for management of the unanticipated difficult intubation. Anaesthesia 2004; 59: 675-94.

32. Peterson GN, Domino KB, Caplan RA, Posner KL, Lee LA, Cheney $F W$. Management of the difficult airway: a closed claims analysis. Anesthesiology 2005; 103: 33-9.

33. Dunn S, Connelly NR, Robbins L. Resident training in advanced airway management. J Clin Anesth 2004; 16: 472-6.

34. Hagberg CA, Greger J, Chelly JE, Saad-Eddin HE. Instruction of airway management skills during anesthesiology residency training. J Clin Anesth 2003; 15: 149-53.

35. Hung $O$. Airway management: the good, the bad, and the ugly. Can J Anesth 2002; 49: 767-71.

36. Goldmann K, Ferson DZ. Education and training in airway management. Best Pract Res Clin Anaesthesiol 2005; 19: 717-32.

37. Redfern $N$, Bartley $C$. Trainee and training issues. Best Prac Res Clin Anaesthesiol 2006; 20: 619-35.

38. Bridges $M$, Diamond $D L$. The financial impact of teaching surgical residents in the operating room. Am J Surg 1999; 177: $28-32$.

39. Jensen AR, Wright AS, Levy AE, et al. Acquiring basic surgical skills: is a faculty mentor really needed? Am J Surg 2009; 197 : 82-8.

40. Ahlberg $G$, Kruuna $O$, Leijonmarck $C E$, et al. Is the learning curve for laparoscopic fundoplication determined by the teacher or the pupil? Am J Surg 2005; 189: 184-9.

41. Ericsson $K A$. Deliberate practice and the acquisition and maintenance of expert performance in medicine and related domains. Acad Med 2004; 79: S70-81.

42. Pott LM, Santrock D. Teaching without a teacher: developing competence with a Bullard laryngoscope using only a structured self-learning course and practicing on a mannequin. J Clin Anesth 2007; 19: 583-6.

43. Pott LM, Murray WB. Review of video laryngoscopy and rigid fiberoptic laryngoscopy. Curr Opin Anaesthesiol 2008; 21: $750-8$.

44. Thong SY, Lim Y. Video and optic laryngoscopy assisted tracheal intubation-the new era. Anaesth Intensive Care 2009; 37: 219-33.

45. Rai MR, Dering A, Verghese C. The Glidescope system: a clinical assessment of performance. Anaesthesia 2005; 60: 60-4.

46. Hirabayashi $Y$, Seo $N$. Tracheal intubation by non-anaesthetist physicians using the Airway Scope. Emerg Med J 2007; 24: $572-3$.

47. Howard-Quijano KJ, Huang YM, Matevosian R, Kaplan MB, Steadman $R H$. Video-assisted instruction improves the success rate for tracheal intubation by novices. Br J Anaesth 2008; 101: 568-72.

48. Low D, Healy D, Rasburn N. The use of the Berci DCI Video Laryngoscope for teaching novices direct laryngoscopy and tracheal intubation. Anaesthesia 2008; 63: 195-201.

49. Shulman GB, Nordin NG, Connelly NR. Teaching with a video system improves the training but not subsequent success of tracheal intubation with the Bullard laryngoscope. Anesthesiology 2003; 98: 615-20. 
50. Smith JE, Fenner SG, King MJ. Teaching fibreoptic nasotracheal intubation with and without closed circuit television. Br J Anaesth 1993; 71: 206-11.

51. Wheeler $M$, Roth AG, Dsida RM, et al. Teaching residents pediatric fiberoptic intubation of the trachea: traditional fiberscope with an eyepiece versus a video-assisted technique using a fiberscope with an integrated camera. Anesthesiology 2004; 101: 842-6.

52. Naik VN, Matsumato ED, Houston P, et al. Fiberoptic orotracheal intubation on anesthetized patients: do manipulation skills learned on a simple model transfer into the operating room? Anesthesiology 2001; 95: 343-8.

53. Rosenthal E, Owen $H$. An assessment of small simulators used to teach basic airway management. Anaesth Intensive Care 2004; 32: 87-92.

54. Friedmann Z, You-Ten KE, Bould MD, Naik V. Teaching lifesaving procedures: the impact of model fidelity on acquisition and transfer of cricothyrotomy skills to performance on cadavers. Anesth Analg 2008; 107: 1663-9.

55. Matsumoto ED, Hamstra SJ, Radomski SB, Cusimano MD. The effect of bench model fidelity on endourological skills: a randomized controlled study. J Urol 2002; 167: 1243-7.

56. Grober ED, Hamstra SJ, Wanzel KR, et al. The educational impact of bench model fidelity on the acquisition of technical skill: the use of clinically relevant outcome measures. Ann Surg 2004; 240: 374-81.

57. Kory PD, Eisen LA, Adachi M, Ridaudo VA, Rosenthal ME, Mayo $P H$. Initial airway management skills of senior residents: simulation training compared with traditional training. Chest 2007; 132: 1927-31.

58. Seymour NE, Gallagher AG, Roman SA, O'Brien MK, Bansal VK, Andersen $D K$. Virtual reality training improves operating room performance. Results of a randomized, double-blind study. Ann Surg 2002; 236: 458-64.

59. Goldman K, Steinfeldt T. Acquisition of basic fiberoptic intubation skills with a virtual reality simulator. J Clin Anaesth 2006; 18: $173-8$.

60. Colt HG, Crawford SW, Galbraith O III. Virtual reality bronchoscopy simulation: a revolution in procedural training. Chest 2001; 120: 1333-9.

61. Rowe $R$, Cohen $R A$. An evaluation of a virtual reality airway simulator. Anesth Analg 2002; 95: 62-6.

62. Plummer $J L$, Owen $H$. Learning endotracheal intubation in a clinical skills learning center: a quantitative study. Anesth Analg 2001; 93: 656-62.

63. De Oliviera Filho GR. The construction of learning curves for basic skills in anesthetic procedures: an application for the cumulative sum method. Anesth Analg 2002; 95: 411-6.
64. Grantcharov TP, Funch-Jensen P. Can everyone achieve proficiency with the laparoscopic technique? Learning curve patterns in technical skills acquisition. Am J Surg 2009; 197: 447-9.

65. Kenton $K$. How to teach and evaluate learners in the operating room. Obstet Gynecol Clin North Am 2006; 33: 325-32.

66. Wang HE, Seitz SR, Hostler D, Yealy DM. Defining the learning curve for paramedic student endotracheal intubation. Prehosp Emerg Care 2005; 9: 156-62.

67. Tatiyanupunwong $S$. Optimum cases for predicting the success rate of endotracheal intubation in Thammasat University's medical students. Thamassat Med J 2008; 8: 436-44.

68. Mulcaster JT, Mills J, Hung OR, et al. Laryngoscopic intubation: learning and performance. Anesthesiology 2003; 98: 23-7.

69. Konrad C, Schupfer G, Wietlisbach M, Gerber H. Learning manual skills in anesthesiology: is there a recommended number of cases for anesthetic procedures? Anesth Analg 1998; 86: 635-9.

70. Smith JE, Jackson AP, Hurdley J, Clifton PJ. Learning curves for fibreoptic nasotracheal intubation when using the endoscopic video camera. Anaesthesia 1997; 52: 101-6.

71. Hopper AN, Jamison MH, Lewis WG. Learning curves in surgical practice. Postgrad Med J 2007; 83: 777-9.

72. Cook JA, Ramsay CR, Fayers $P$. Statistical evaluation of learning curve effects in surgical trials. Clin Trials 2004; 1: 421-7.

73. Kestin IG. A statistical approach to measuring the competence of anaesthetic trainees at practical procedures. Br J Anaesth 1995; 75: 805-9.

74. Harrison MJ. Tracking the early acquisition of skills by trainees. Anaesthesia 2001; 56: 995-8.

75. Fletcher GC, McGeorge P, Flin RH, Glavin RJ, Maran NJ. The role of non-technical skills in anaesthesia: a review of the current literature. Br J Anaesth 2002; 88: 418-29.

76. Flin R, Maran N. Identifying and training non-technical skills for teams in acute medicine. Qual Saf Health Care 2004; 13: i80-4.

77. Sundar E, Sundar S, Pawlowski J, Blum R, Feinstein D, Pratt S. Crew resource management and team training. Anesthesiol Clin 2007; 25: 283-300.

78. Fletcher G, Flin R, McGeorge P, Glavin R, Maran NJ, Patey $R$. Anaesthetists Non-Technical Skills (ANTS): evaluation of a behavioural marker system. Br J Anaesth 2003; 90: 580-8.

79. Smith HM, Kopp SL, Jacob AK, Torsher LC, Hebl JR. Designing and implementing a comprehensive learner-centered regional anesthesia curriculum. Reg Anesth Pain Med 2009; 34: 88-94. 